\title{
Influence of Different Mulberry (Morus spp.) Varieties on Rearing Performance of Mulberry Silkworms (Bombyx mori L.) (Lepidoptera: Bombycidae) in Melkassa Agricultural Research Center, Ethiopia
}

\author{
Shifa $\mathbf{K}^{*}$, Terefe $\mathbf{M}$, Ibrahim A and Tilahun A \\ Melkassa Agricultural Research Center, P.O.Box 436, Adama, Ethiopia \\ *Corresponding author: Kedir Shifa, Melkassa Agriculturl Research Center, Melkassa \\ Agricultural Research Center P.O. Box, 436, Adama, Ethiopia, Tel: +251911384487; Email: \\ kedirsh01@gmail.com
}

\section{Research Article}

Volume 3 Issue 4

Received Date: May 25, 2018

Published Date: June 05, 2018

\section{Abstract}

Growth, development and yield of silkworms depend on the availability and supply of preferred host plants with required nutritional characteristics. Since mulberry silkworms feed only on mulberry leaves and the mulberry varieties will vary nutritionally, different mulberry varieties will have variable influence on the performance of mulberry silkworms. Therefore, this experiment was conducted with an objective to know the influence of different mulberry varieties on rearing performance of mulberry silkworms. In the present study, six different mulberry varieties (K-2, S-13, M-4, Nekemte, Jimma and local check) were evaluated for their effect on a bivoltine mulberry silkworm (Bombyxmori L.) in Melkassa Agricultural Research Center (MARC), East- Shewa zone of Oromia Regional State, Ethiopia. The experiment was arranged in Completely Randomized Design (CRD) with three replications. Two hundred worms were used in each treatment. As a result, significant difference was obtained in rearing performance of mulberry silkworms when leaves of these mulberry varieties were served as feed material. Among mulberry varieties fed to mulberry silkworm, a variety named S-13 was found to be superior as compared to others by revealing a silkworm rearing performance characters of $2.5303 \mathrm{~g}$ matured larval weight, $1.11167 \mathrm{~g}$ cocoon weight, $0.92433 \mathrm{~g}$ pupal weight, $0.187 \mathrm{~g}$ shell weight and $16.822 \%$ silk ratio, $81.5 \%$ effective rate of rearing (ERR), 305.467 eggs as fecundity and $70.0 \%$ hatchability of eggs. The variety named K-2 was also found to be the 2nd best choice next to S-13 from this experiment. Thus, the result obtained by feeding varieties known by S-13 and K-2will help for improving the rearing performance of mulberry silkworms with emphasis to economic traits and therefore they are recommended for further research and development works of mulberry sericulture in Ethiopia.

Keywords: Mulberry varieties; Mulberry silkworm (Bombyx mori); Rearing Performance 


\section{Open Access Journal of Agricultural Research}

\section{Introduction}

Silk is a functional term used to describe natural protein fibers that are secreted by arthropods [1]. The industrial and economic importance of silk production contributed to the silkworm promotion all over the world [2]. Silk production has the potential to make a significant contribution to the economy of many other countries where there is surplus labor, low-costs of production and a willingness to adopt new technologies [3].

In Ethiopia, silk has played an important part in the social and religious life of Ethiopians from the earliest days of history. However, the silk yarns used were imported from India, Arabia and China though the country has diversified climate and vegetation to support diversified options of silk production industry [4]. Belli also reported that there were no known records of silk being produced in the country until 1930's but explained the existence of possibility of silkworm rearing in different parts of the country if worms are protected against night cold [5].

Therefore, several research and development efforts were conducted on silkworms in Ethiopia in the past decade including mulberry silkworms (Bombyxmori). As a result, silk production from mulberry silkworms is practiced in some parts of the country recently [6].

The Mulberry silkworm, Bombyxmori L., is the most exploited and commercialized non silkworms.. It can be reared in doors throughout the year to produce mulberry silk (Joshi, 1992).Mulberry (Morus spp.) is the primary and only food plant, which can ensure production of good quality cocoons. Similarly, Dayashankar, Devaiahet al. have reported the variable influence of mulberry on overall performance of silkworms $[7,8]$.

Mulberry is considered as commercial crop because its stems, leaves, roots will be used for different purposes in agricultural, industrial and pharmaceutical purposes. In addition with cultivated lands, it is also found along road shoulders and fences as well as intercropped with other crops [6].

On the other hand, Mulberry silkworm larvae obtain nutrients from leaves to build up body, sustain life, spin cocoons and produce eggs from leaves of mulberry. Feeding silkworms provides energy for growth, development, reproduction and many of its other needs. Such nutritional requirement in food consumption have direct impact on the overall genetic traits such as larval and cocoon weight, amount of silk production, pupation and reproductive traits [9].

Thus, successful sericulture depends on increased production of leaves with high nutritive values. It has also been observed that the growth and development of silkworms and quality of silk cocoon produced are directly influenced by the variety and quality of leaves fed to the worms [9]. Bose, et al. and Sannappa and Jayaramaiah also stated the importance of quality leaves and good nutrition during silkworm rearing has effect on growth and development of silkworm and overall silk production $[10,11]$.

However, mulberry shows a wide range of diversity in nature. It has been well recognized that morphological features and nutritive values of the leaves differ significantly from variety to variety and over locations. Kumar, D studied mulberry varieties and observed variation in leaf yield and other plant parameters in different varieties. Murthy VNY, et al. has also reported significant variation in performance of mulberry silkworms when different mulberry varieties were fed $[12,13]$.

Hence, it can be recognized that selection of mulberry varieties is an important criterion for better growth and development to obtain better fecundity, silkworm development and cocoon productivity. However, the performance of the mulberry silkworm with regard to mulberry genotype differences has not been identified and documented in Ethiopia. This work, therefore, was carried out with objectives to study the influence of mulberry varieties on rearing performance of mulberry silkworms and to find out a promising mulberry genotype in respect to economic traits.

\section{Materials and Methods}

The study was conducted in Melkassa Agricultural Research Center (MARC), which is one of the Research Centers under the Ethiopian Institute of Agricultural Research (EIAR). It is found $117 \mathrm{kms}$ away from Addis Ababa and $17 \mathrm{~km}$ to southeast of Nazareth in the EastShewa zone of Oromia region. It is located $8^{\circ} 24^{\prime} \mathrm{N}$ latitude and $39^{\circ} 12^{\prime}$ E longitude having an elevation of 1500 meters above sea level and a mean annual rainfall of $770 \mathrm{~mm}$.

One bivoltine mulberry silkworm breed known by Kenya 1 was used for this experiment and it was reared 


\section{Open Access Journal of Agricultural Research}

on the six mulberry varieties. The experiment was arranged in Completely Randomized Design (CRD) in three replications. In each replication, 200 worms were used and allowed to complete the larval period. As per the rearing recommendations of silkworms by Dayashankar, the silkworm rearing room and equipments were cleaned, washed and disinfected with $2 \%$ formalin solution at the rate of $800 \mathrm{ml}$ per $10 \mathrm{~m} 2$ before the commencement of the experiment (rearing) [7]. This breed was reared following cellular rearing techniques starting from brushing till cocoon spinning on these varieties. Tender leaves of mulberry were fed four times a day until the larvae ends II instar stage, and semi tender leaves to III instar while more matured leaves were fed to IV and V instar larvae.

As used by Singh and Benchamin, matured worms were picked and mounted on the mount ages for spinning. On the six day of spinning, the cocoons will be harvested, counted and weighed [14].

Rearing parameters like body weight of single mature larvae $(\mathrm{g})$, percentage of egg hatchability and effective rate of rearing, cocoon traits (single cocoon, pupal and shell as well as silk ratio), and fecundity (number of eggs per female) were recorded to find out rearing performance of the worms on the mulberry varieties.

The following formulae adopted by Singh and Benchamin were used for data on rearing performance when required [14].

\section{Survival rate $=\underline{\text { Number of larva survived larva }} \times 100$ \\ Number of larva brushed}

Hatching percent $=($ Number of normal eggs- Number of non hatched egg $) \times 100$

Number of normal eggs

Silk ratio $=$ Weight of shell $\quad \times 100$

Weight of fresh cocoon

Effective rate of rearing $(E R R)=($ No. of larvae spinning cocoon $\times 100$

No. of larvae brushed

Finally, the data were analyzed statistically (one-way CRD) by using SAS software at $5 \%$ level of significance [15]. LSD was used as a tool for mean separation.

\section{Results}

In this experiment, characters of mulberry silkworm rearing like hatching percentage, larval duration, larval weight, single cocoon weight, single shell weight, shell (silk) ratio, larval duration, fecundity, effective rate of rearing (ERR) and survival and showed significant differences when the mulberry silkworm fed with different mulberry varieties. The results of silkworm rearing characters fed on different mulberry varieties are summarized as follows.

\section{Fecundity}

Silkworm fed on S-13 showed significantly higher fecundity (305.467) followed by M-4 (289.867). The local check (259.533) was lower performing compared to the rest mulberry varieties for fecundity of mulberry silkworms (Figure 1). 


\section{Open Access Journal of Agricultural Research}

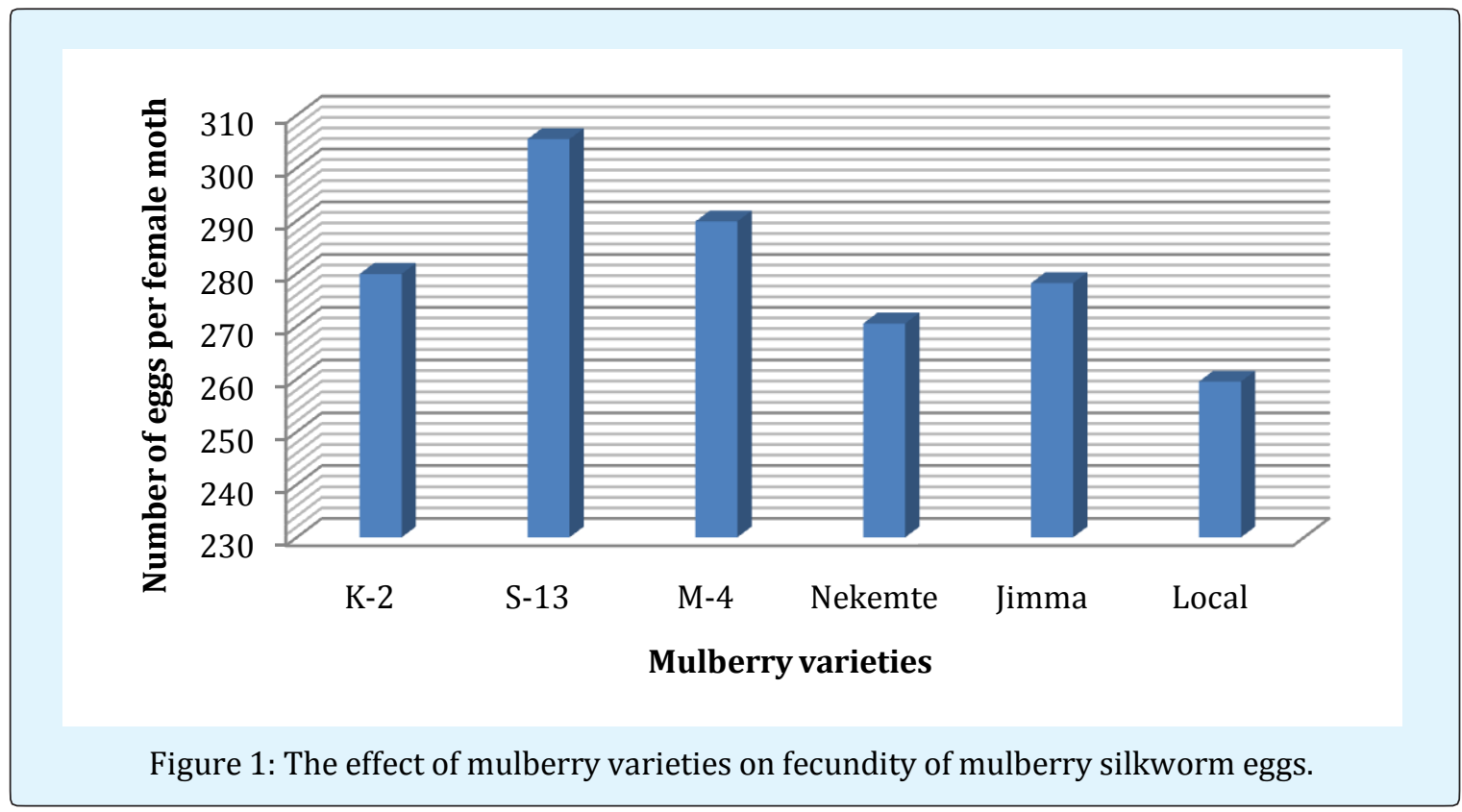

\section{Percentage Hatching of Eggs}

Hatching rate of silkworm eggs in to larva showed significant variation when a silkworm fed on different mulberry varieties ranging from $62.02 \%$ to $75.33 \%$. The maximum hatching was recorded in M-4 (75.33 \%) followed by K-2 (70.7033\%) and S-13 (70.00\%) (Table 1).

\section{Effective rate of rearing (ERR)}

ERR has also revealed a significant difference when mulberry silkworm fed on different mulberry varieties. Mulberry silkworm fed on S-13 (81.50\%) recorded higher ERR closely followed by M-4 (77.0 \%) and Jimma $(74.02 \%)$. The least ERR was obtained from local check (68.833\%) (Table 1).

\begin{tabular}{|c|c|c|}
\hline Treatment & Hatching percent of eggs & Effective rate of rearing (\%) \\
\hline K2 & $70.7033 \mathrm{~b}$ & $75.56667 \mathrm{c}$ \\
\hline S13 & $70.0000 \mathrm{~b}$ & $81.50000 \mathrm{a}$ \\
\hline M4 & $75.3300 \mathrm{a}$ & $77.00000 \mathrm{~b}$ \\
\hline Nekemte & $65.4300 \mathrm{c}$ & $73.67000 \mathrm{e}$ \\
\hline Jimma & $62.0200 \mathrm{c}$ & $74.02000 \mathrm{~d}$ \\
\hline Local & $65.0000 \mathrm{c}$ & $68.83333 \mathrm{f}$ \\
\hline SE & 1.07154353 & 0.92527588 \\
\hline $\mathrm{CV}(\%)$ & 0.637592 & 0.157055 \\
\hline $\mathrm{Pr}$ & $<.0001$ & $<.0001$ \\
\hline
\end{tabular}

Table 1: Effects of mulberry varieties on silkworm egg hatchability and effective rate of rearing.

Note: - Means followed by the same letter within a column are not significantly different from each other at $5 \%$ level of probability (LSD mean comparison test).

\section{Larval Weight}

Matured worms fed on S-13 recorded significantly higher larval weight $(2.5303 \mathrm{~g})$ and $8.17 \mathrm{~g}$ respectively.
However, the least larval weight was obtained from worms fed on local check (2.00633 g). 


\section{Open Access Journal of Agricultural Research}

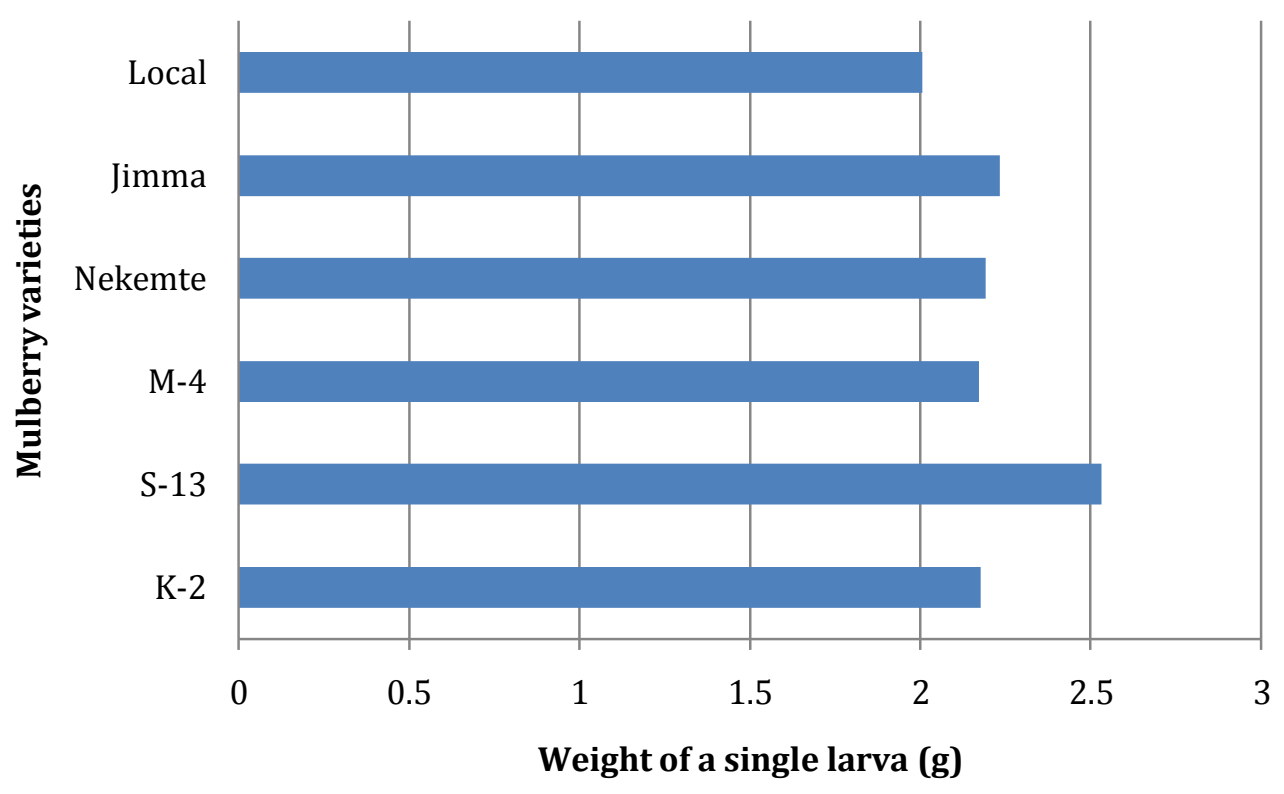

Figure 2: The effect of mulberry varieties on larval weight of mulberry silkworms.

\section{Duration of larval stage}

Significantly longer larval duration (34.0033 days) was recorded in the worms fed on the local check followed by
Nekemete (34.00 days) and Jimma (34.00 days). However, the lowest duration was recorded when worms fed on S13 (31.50 days) and $\mathrm{K}-2$ (32.00 days).

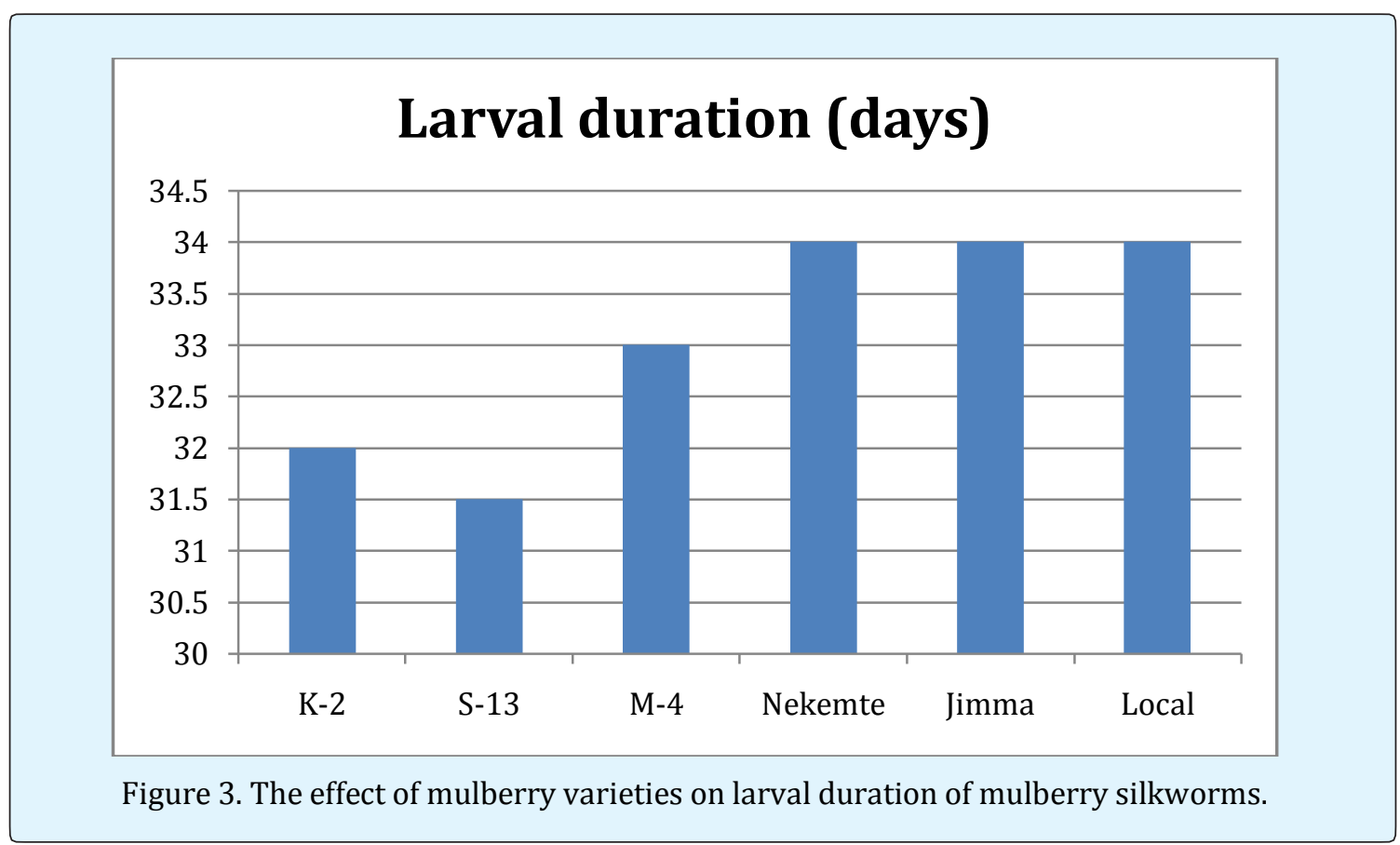

Shifa K, et al. Influence of Different Mulberry (Morus spp.) Varieties on Rearing Performance of Mulberry Silkworms (Bombyx mori L.) (Lepidoptera: Bombycidae) in Melkassa Agricultural 


\section{Open Access Journal of Agricultural Research}

\section{Cocoon weight, pupal weight, shell weight and silk ratio}

In accordance to yield, maximum single cocoon weight was recorded in those larvae which were fed on the leaves of S-13 (1.11167 g). The minimum single cocoon weight $(0.86567 \mathrm{~g})$ was recorded from larvae fed on local check. Similarly, the highest single pupa weight was obtained from those fed on S-13 (0.92433 g) and the lowest was obtained from those fed on local $(0.7300 \mathrm{~g})$.
Single shell weight of a cocoon revealed significant variation when fed with the different mulberry accession. S-13 revealed significantly higher shell weight $(0.187 \mathrm{~g})$ but local check showed the least shell weight $(0.136 \mathrm{~g})$. However, there was no statistically significant variation in regard the effect of mulberry varieties to shell (silk) ratio of the silkworms.

\begin{tabular}{|c|c|c|c|c|}
\hline Treatment & Cocoon weight (gram) & Pupal weight (gram) & Shell weight (gram) & Silk ratio (\%) \\
\hline K-2 & $1.03000 \mathrm{~b}$ & $0.86467 \mathrm{~b}$ & $0.16833 \mathrm{ab}$ & 16.350 \\
\hline $\mathrm{S}-13$ & $1.11167 \mathrm{a}$ & $0.92433 \mathrm{a}$ & $0.18700 \mathrm{a}$ & 16.820 \\
\hline $\mathrm{M}-4$ & $1.01333 \mathrm{~b}$ & $0.83000 \mathrm{~b}$ & $0.16333 \mathrm{ab}$ & 16.123 \\
\hline Nekemte & 1.00133 & $0.84300 \mathrm{~b}$ & $0.15867 \mathrm{bc}$ & 15.890 \\
\hline Jimma & $1.00600 \mathrm{~b}$ & $0.84467 \mathrm{~b}$ & $0.16133 \mathrm{bc}$ & 16.053 \\
\hline Local & $0.86567 \mathrm{c}$ & $0.73000 \mathrm{c}$ & $0.13600 \mathrm{c}$ & Local \\
\hline SE & 0.018687 & 0.014639 & 0.004618 & 0.324628 \\
\hline CV (\%) & 3.194023 & 2.602669 & 8.825915 & 9.785895 \\
\hline Pr & $<.0001$ & $<.0001$ & 0.0238 & 0.9654 \\
\hline
\end{tabular}

Table 2: Effects of mulberry varieties on cocoon parameters of mulberry silkworms.

Note: Means followed by the same letter within a column are not significantly different from each other at $5 \%$ level of probability (LSD mean comparison test)

\section{Discussion}

Study on rearing performance of mulberry silkworms as influenced by mulberry varieties was conducted and differences were evaluated based on different response variables measured from silkworms fed on these varieties. In this investigation, the results indicated that mulberry varieties viz. K-2, S-13, M-4, Nekemte, Jimma and local check resulted in significant variation in rearing performance of mulberry silkworms. It is well known that insects growth and development do vary due to the varied level of feed and nutrient intake, quality of the feed and total biochemical composition of the leaf supplied to the insects [16].

In general, among mulberry varieties studied, a silkworm fed on S-13 provided highest larval weight and ERR as well as highest cocoon weight, shell weight and pupal weight and silk ratio as well as ERR with medium and above medium record for hatching percent of eggs and fecundity. In addition, the variety named K-2 has been found to consistently show a better record in most of the indicated response variables of the silkworms. Therefore, it could be considered as a 2nd best choice in improving qualitative and quantitative gains from mulberry silkworms. The difference in rearing performance of silkworms could be attributed to nutritional composition; such as moisture (glossiness with high wax), proteins, carbohydrates, fats, minerals, vitamins, etc. of the leaves of mulberry varieties. Similar studies conducted by Patilet al. and Jayaramaiah and Sannappa (1998) and Sengupta et al. in India confirm such differences in larval, cocoon and post-cocoon traits of eri silkworms when fed with different castor genotypes [11,16-18]. Besides, Sanappa et al mentioned variation in larval, cocoon and grainage variables for eri-silkworms when fed on castor genotypes in South India [11]. They recommended Aruna castor variety for rearing of eri silkworms for commercial traits. Eri silkworms silk production depends on the amount of feed provided to the leaves, the rate at which the feed is provided and quantity of feed consumed by the larvae. These intern influence the growth rate, development time, body weight, survival percentage, intensity of silk secretion, adult emergence, mating success and extent of reproduction [18-22].

However, mulberry variety M-4 fed worms resulted in highest egg fecundity and hatchability but was not high yielding in commercial traits compared to S-13. It could 


\section{Open Access Journal of Agricultural Research}

be justified by presence of specific nutrients like minerals which could contribute more to grain age parameters or otherwise by presence of some anti-nutritional components like protein binding tannins in its leaves which affect larval or cocoon traits. Similar findings by Jayaramaiah and Sannappa confirm castor genotype differences on feeding efficiency of eri silkworms [11].

However, local variety fed silkworms recorded medium and below medium values for most rearing performance indicators. It may be because its leaf contains less of important nutrients and/or has lower efficiency to be converted to larval and cocoon traits on mulberry silkworms.

Therefore, the present study revealed that $S-13$ to be the most promising mulberry variety among the treatments, which showed $1.11167 \mathrm{~g}, 0.187 \mathrm{~g}$ and 16.82 $\%$,single cocoon weight, single shell weight and shell ratio percentage, respectively. It will be considered for mulberry sericulture efforts in Ethiopia. On the other hand, K-2variety was observed to be considered as a next option for the same purpose in cases or areas where conditions for its better leaf quality and quantity production can be attained. However, in related studies conducted in India by Murthy, V.N.Y. et al, it is observed that single cocoon weight of $1.71 \mathrm{~g}, 0.35 \mathrm{~g}$ and $21.18 \%$, single cocoon weight, single shell weight and shell ratio percentage, respectively on $\operatorname{Tr} 8$ mulberry variety [13]. It indicated that the productivity level in our research is very low either due to use of poor varieties of silkworms and mulberry plants or reduced management practices.

\section{Conclusion and Recommendation}

As a result, the present study reveals that mulberry varieties have strong influence on mulberry silkworm rearing performance. Hence, selection of mulberry varieties for rearing mulberry silkworms based up on rearing performance of mulberry silkworms is very important in order to get better egg production, larval development and cocoon yield.

Therefore, S-13 was found to be the best promising mulberry variety in respect to rearing performance indicators of mulberry silkworm followed by K-12. Therefore, S-13 (1st option) and K-2 (2nd option) varieties of mulberry will be recommended for mulberry silkworm research and development efforts in future.
However, more research should also be carried out to support the current findings in consideration with different pest and disease management options, agronomic practices and foliar composition studies of different mulberry varieties. In addition, additional research will be required on feeding and conversion efficiency of mulberry silkworms using mulberry varieties as a feed.

\section{References}

1. Chowdhary SN (2006) Host plants of eri silkworm (Samia ricini Boiduval): Their distribution economic and prospects for exploitation. In: Proceeding of National workshop on Eri food plants pp: 28-37.

2. Ramesha C, Anuradha CM, Lakshmi H, Kumari SS, Seshagiri SV, et al. (2010) Nutrigenetic traits analysis for the identification of nutritionally efficient silkworm germplasm breeds. Biotechnology 9(2): 131-140.

3. Hajare TN, Jadhav AD, Venugopalan $M$, Patil NG, Chaturvedi A, et al. (2007) Evaluation of sericulture for augmenting agricultural income of marginal farmers in semi-arid region of India. In: Proceedings of International Conference on Sericulture Challenges in the $21^{\text {st }}$ Century and the 3rd BACSA meeting.

4. Spring C, Hudson J (2002) Silk in Africa: Ethiopia. University of Washington Press, Seattle.

5. Belli C (1947) Mission of the Ente Nazionale sericole of Italy. Sericologia 10: 13-17.

6. Metaferia HY, Amanuel T, Kedir S (2007) Scaling up of silk production technologies for employment and income generation in Ethiopia. Ethiopian Institute of Agricultural Research.

7. Dayashankar KN (1982) Performance of eri silkworm, Samia cynthia ricini Boisduval on different host plants and economics of rearing on castor under Dharwad conditions. M.Sc. Thesis, University of Agricultural Sciences, Bangalore, pp.60-86.

8. Devaiah MC, Rajashekhargouda R, Suhas Y, Govindan $\mathrm{R}$ (1985) Growth and silk production in Samia cynthia ricini Boisduval as fed on four different host plants. Ind J Seril 24: 33-35. 


\section{Open Access Journal of Agricultural Research}

9. Krishnaswami S, Asan M, Sriharn TP (1970) Studies on the quality of mulberry leaves and silkworm cocoon crop production. Ind J Seric 9: 11-25.

10. Bose PC, Majumder SK, Sengupta K (1991) A comparative biochemical study of six mulberry (Morus alba L.) varieties. Indian. J Seri 30: 83-87.

11. Sannappa B, Jayaramaiah J (1999) Mineral Constituents of Selected Genotypes of Castor, Ricinus communis L. Mysore J agric Sci 33: 157-161.

12. Kumar D, Rajput S, Kour A, Kumar A, Danish A, et al. (2016) Evaluation and characterization of improved mulberry genotypes. J Glob Biosciences 5(4): 38843891.

13. Veerapura Y, Murthy N, Ramesh HL, Lokesh G, Rajappa M (2013) Assessment of six Mulberry (Morus) Germplasm varieties through Moulting and Bioassay parameters by using Crossbreed Silkworms Bombyx mori L. for Commercial Exploitation in Kolar District, Karnataka, India. Int Res J Biological Sci 2(9): 69-75.

14. Singh KC, Benchamin KV (2002) Biology and ecology of the eri silkmoth Samia ricini Donovan (Saturniidae): Bullet Ind Acad Seric 6: 20-33.

15. SAS Institute Inc (1999-2000) SAS/STAT users' guide. SAS Institute Cary.

16. Sengupta T, Chakravorty D, Sengupta D, Sengupta AK, Das SK (2007) Screening of some improved castor genotypes for quality parameters in gangetic alluvial soil of West Bengal. Agric Sci Dig 28: 268-270.

17. Patil RR, Kusugal S, Ankad G (2009) Performance of eri silkworm, Samia cynthia ricini Boisd on few food plants. Karnataka J Agric Sci 22(1): 220-221.

18. Jayaramaiah M, Sannappa B (1998) Correlation Coefficients Between Foliar Constituents of Castor Genotypes and Economic Parameters of the Eri Silkworm, Samia cynthia ricini Boisduval (Lepidoptera: Saturniidae). The third Int Conf Wild Silkmoths pp: 162-194.

19. Jayaraj S (2004) Eri culture in Tamil Nadu, Kerala and Pondichery states: Some experiences. In: Proceeding of Workshop on Prospects and Development of Ericulture, University of Agricultural Sciences, Dharwad pp: 10-29.

20. Joshi KL (1992) Evaluation of Diets for Larvae of the Eri Silkworm, Samia cynthia ricini (Lepidoptera: Saturniidae). Ind J Seric 31: 49-51.

21. Patil GM, Kulkarni KA, Patil RK, Badiger KS (1998) Performance of Eri Silkworm, Samia Cynthia Ricini Boisd on different castor genotypes. Int. Conf Wild Silkmoths pp: 193-195.

22. Raghavaiah CV (2003) Prospects of Eri silk (Philosomia ricini) production along with castor beans (Ricinus communis L.) and Tapioca (Manihot utilisimma) production in Andhra Pradesh. Ind Silk 42: 33-35. 